\title{
INTERLÚDIO EUFÓRICO E FRAGMENTAÇÃO DO "EU": APROXIMAÇÕES \\ E DISTANCIAMENTOS ENTRE A “ODE TRIUNFAL” DE ÁLVARO DE CAMPOS E AS TESES FUTURISTAS DE MARINETTI
}

Thiago Mio Salla ${ }^{1}$

RESUMO: O presente artigo tem por objetivo analisar a segunda fase da poesia de Álvaro de Campos, heterônimo de Fernando Pessoa, com foco específico no estudo da Ode Triunfal, poema no qual o artista glorifica, em tom eufórico, as descobertas tecnológicas e científicas do mundo moderno. Nesse processo, Campos advoga em favor de um "eu" fragmentário, capaz de mimetizar o caráter prismático do turbilhão de sensações do mundo moderno, colocando-se como uma espécie de porta-vOz do processo de despersonalização empreendido pelo próprio Pessoa. Diante disso, convém examinar tal produção, com foco num dos principais intertextos com os quais ela dialoga: as teses futuristas de F. T. Marinetti. Assim, procurar-se-ão apontar aproximações e distanciamentos entre o referido texto pessoano e as diretrizes vanguardistas traçadas pelo teórico italiano em seus principais panfletos combativos.

PALAVRAS-CHAVE: Fernando Pessoa; Álvaro de Campos; Ode Triunfal; Marinetti; Futurismo

EUPHORIC INTERLUDE AND FRAGMENTATION OF SELF: SIMILARITIES AND DIFFERENCES BETWEEN THE "ODE TRIUNFAL"
BY ÁLVARO DE CAMPOS AND MARINETTI'S FUTURISTIC THESES

ABSTRACT: This article aims to analyze the second phase of the poetry of Alvaro de Campos, Fernando Pessoa heteronomous, with a particular focus on the study of the Ode Triunfal, a poem in which the artist glorifies, in an euphoric tone, technological and scientific discoveries of the modern world. In this process, Campos argues in favor of one fragmented personality, able to represent the prismatic character of the huge flow of sensations of the machine age, standing as a sort of spokesman for the depersonalization process undertaken by Pessoa. Given this fact, such production should be examined focusing one of the most important intertexts with which it dialogues: F. T. Marinetti's futuristic theses. Thus this paper will try to point similarities and differences between this Pessoa's text and the vanguard guidelines outlined by the Italian theorist in his combative pamphlets.

KEYWORDS: Fernando Pessoa; Álvaro de Campos; Ode Triunfal; Marinetti; Futurism.

\footnotetext{
${ }^{1}$ Doutor em Ciências da Comunicação pela Escola de Comunicações e Artes (USP) e doutorando em Letras pela Faculdade de Filosofia Letras e Ciências Humanas (USP).
} 
Como se sabe, dos heterônimos de Fernando Pessoa, Álvaro de Campos² é aquele que apresenta o percurso intelectual mais disforme. Visto em perspectiva, seu desenho interno é pautado por inflexões, o que permite dividir sua poesia em três fases distintas (COELHO, 1977, p. 66). A primeira delas apresentaria uma herança mais marcadamente decadentista, como se pode perceber no poema Opiário ${ }^{3}$, em que predominam a "nostalgia de além, a morbidez snob de um saturado de civilização, a embriaguez do ópio e dos sonhos dum Oriente que não há, o horror à vida (...) ao ritmo dos decassilabos agrupados em quadras” (Idem, p. 67). Em seguida, Ode Triunfal inaugura a segunda fase da poesia de Álvaro de Campos. Nela, o poeta se mostra seduzido pela vertigem das sensações do mundo moderno, aproximando-se das propostas futuristas, sobretudo no que diz respeito à celebração da máquina e da velocidade em poemas febricitantes, tal como se verá em detalhes mais à frente. Já a terceira fase seria marcada pela disforia e pelo niilismo, na qual a percepção delirante do mundo exterior e os excessos dionisíacos anteriores cederiam espaço para um processo de autoconscientização e de introspecção analítica. Nesse momento, avulta um olhar retrospectivo, melancólico e abúlico, focado não mais em ilusões redentoras, mas em pensamentos sobre o próprio absurdo de viver, que não obedeceria a nenhum plano prédeterminado.

Diante da sinuosidade dessa trajetória intelectual (mostra do caráter plural do "eu" construído não só pelo autor, mas por seu próprio heterônimo), ganha destaque, pela especificidade, o interlúdio eufórico, situado entre as disforias inicial e final do percurso artístico de Álvaro de Campos. Tal enclave reúne um conjunto de textos que podem ser dispostos numa escala descendente de arroubo e vertigem futurista: abarca as Ode Triunfal (1914) e Ode Marítima (1915?), em que, sobretudo a primeira, torna explícita a glorificação

\footnotetext{
${ }^{2}$ Em carta a Adolfo Casais Monteiro, Pessoa traça, em rápidas pinceladas, a biografia deste heterônimo. "Álvaro de Campos nasceu em Tavira, no dia 15 de outubro de 1890 (às 1:30 da tarde, diz-me o Ferreira Gomes; e, é verdade, pois feito o horóscopo para essa hora, está certo). Este, como sabe, é engenheiro naval (por Glasgow), mas agora está aqui em Lisboa em inatividade (...) Álvaro de Campos é alto (1,75m de altura, mais $2 \mathrm{~cm}$ do que eu), magro e um pouco tendente a curvar-se. Cara rapada (...) entre branco e moreno, tipo vagamente judeu português, cabelo porém liso e normalmente apartado ao lado, monóculo (...) Teve uma educação vulgar de Liceu; depois mandado para Escócia estudar engenharia, primeiro mecânica e depois naval. Numas férias fez a viagem ao Oriente de onde resultou o Opiário. Ensinou-lhe latim um tio beirão que era padre." (PESSOA, 1980, p. 206-7).

${ }^{3}$ Opiário foi publicado no primeiro trimestre de 1915, no número de estreia da revista Orpheu. Contudo, foi intencionalmente datado de março de 1913, com o intuito de documentar e mistificar a primeira fase do heterônimo, na qual são apresentadas todas "as tendências latentes do Álvaro de Campos" (PESSOA, 1946, p. 265).

${ }^{4}$ Poema também publicado no número inaugural da revista Orpheu, no primeiro trimestre de 1915.
} 
da civilização moderna, além de Saudação a Walt Whitman (1915) e Passagem das Horas (1916), poemas mais pessoais e menos trepidantes em que, mesclada ao desencadear impetuoso de sensações do mundo moderno, assoma mais vivamente certa dose do desengano que povoará o terceiro ciclo do poeta. ${ }^{5}$

Curiosamente, nessa fase extática da poesia de Campos, ganha materialidade e amplitude a perspectiva singular de "abolição do dogma da personalidade" no âmbito do próprio heterônimo. Este chega a tematizar o assunto no panfleto Ultimatum, publicado em 1917, na revista Portugal Futurista: "só tem o direito ou o dever de exprimir o que sente, em arte, o indivíduo que sente por vários” (PESSOA, 1990, p. 517). Aqui o sujeito poético e suas criações encontram-se, complementam-se e fecundam-se: o postulado de Campos, de que o artista deveria "sentir por um certo número de Outros todos diferentes uns dos outros" (Idem, p. 518), não passa de reafirmação e justificativa da fragmentação do "eu" levada a termo pelo próprio Pessoa mediante um processo de criação de uma humanidade toda sua (PESSOA, 1966, p. 102). Em outras palavras, pode-se dizer que, nesse ciclo medial de sua trajetória poética, o heterônimo acabava se colocando na condição de portavOz impessoal da proposta de despersonalização empreendida por Pessoa. Daí a importância em se analisar as camadas discursivas que recobrem tal situação de aparente convergência, em que o fixismo da relação eu-outrem volatiliza-se (LOPES, 1969, p. 276).

\section{“Sensacionismo" e a territorialização do futurismo}

Essa proposta de multiplicação da personalidade poética desdobra-se no processo de fragmentação do "eu" em meio à vertigem de sensações do mundo moderno. Tendo em vista a formulação teórica dessa relação, por volta de 1916, praticamente dois anos depois da composição da Ode Triunfal, poema em que o intertexto das teses futuristas de Marinetti se faz sentir com mais intensidade, Pessoa-Álvaro de Campos começa a reunir reflexões sobre a poesia modernista lusitana, definindo o que se denominou de "escola sensacionista". De modo geral, o "sensacionismo" tratou-se da construção episódica e malograda de um "ismo" de origem portuguesa, cuja matriz moderna e cosmopolita procurava dar consistência ao grupo vanguardista lisboeta formado pelo próprio Pessoa (e

\footnotetext{
${ }^{5}$ Em Passagem das Horas, num momento de quebra do êxtase, o poeta chega a destacar: "embora eu quisesse tudo, tudo me faltou" (PESSOA, 1977, p. 353).
} 
seu heterônimo Álvaro de Campos), Mário de Sá-Carneiro, Almada Negreiros, entre outros ${ }^{6}$.

Numa análise ligeira do arcabouço teórico sensacionista, percebe-se que tal corrente imaginada por Pessoa-Campos ${ }^{7}$ tomava a sensação como base do fenômeno artístico. A um só tempo onívoro e sintético, o sensacionismo reivindicava a prerrogativa de "sentir tudo de todas as maneiras" (PESSOA, 1977, p. 347), visando à ascensão extática ao Absoluto, mediante a convergência entre passado, presente e futuro. Nesse processo, caberia ao "eu" poético tomar consciência do desencadear impetuoso de todas as sensações e conferir-lhes valor artístico, na medida em que se deixava arrebatar pelo dinamismo vertiginoso da modernidade. Mais do que mera impressão subjetiva, portanto, o processo sensitivo deveria ser objetivado, na medida em que "a finalidade da arte seria simplesmente aumentar a autoconsciência humana" (PESSOA, 1966, p. 186) ${ }^{8}$.

Conforme expõe o próprio Pessoa, em carta a um editor inglês, o referido sensacionismo descendia do "simbolismo francês"; do "panteísmo transcendentalista português" (faz referência específica à Ode à Luz, de Guerra Junqueiro, com destaque para a fusão entre espírito e matéria presente na obra); e da "baralhada de coisas sem sentido e contraditórias de que o futurismo, o cubismo e outros quejandos são expressões ocasionais, embora, para sermos exactos, descendamos mais do seu espírito do que de sua letra" (PESSOA, 1966, p. 134). Nesse processo de catalogação de influências, por mais que reconheça certa ascendência futurista, percebe-se, em tom autoafirmativo, que a fundamentação teórica do movimento procurava distinguir-se dos postulados de Marinetti. Em outro momento afirma: "Os futuristas são algo de absurdo, como gregos que pretendessem ser modernos e analíticos” (Idem, p. 187).

Contudo, quando se examinam as odes de Álvaro de Campos, sobretudo a Ode Triunfal, o diálogo com o futurismo mostra-se nítido. Conforme salienta Lind, a investida

\footnotetext{
${ }^{6}$ Escritas em 1916, as teses sensacionistas não alcançaram grandes adesões, mesmo entre os escritores modernistas portugueses. Conforme sublinha Lind, isso ocorrera porque o sensacionismo estava demasiado ajustado à poesia de Álvaro de Campos para poder ser incorporado por outros artistas (LIND, 1981, p. 202-3). Pouco tempo depois, a doutrina cai no esquecimento e Pessoa desiste de completar e expandir as propostas dela (Idem, p. 203).

${ }^{7}$ Quer um quer outro assinam textos procurando fundamentar a nova escola (ver PESSOA, 1966, p. 111218).

${ }^{8}$ Entre 1924 e 1925, no artigo “Apontamentos para uma estética não-aristotélica”, publicado nos números três e quatro da revista Athena, Álvaro de Campos passa a definir sua arte segundo outra terminologia: sai de cena o "sensacionismo", e sua produção poética passa a ser apresentada como "não-aristotélica". As linhas mestras de tal perspectiva seriam a força, a sensibilidade e a unidade (PESSOA, 1980, p. 252-4). As origens da nova corrente poderiam ser encontradas em Whitman, Caeiro e nas odes do próprio Campos. A remissão ao futurismo é apagada.
} 
de Pessoa-Campos contra qualquer confusão entre o sensacionismo e a escola de Marinetti “não passa de um grito no deserto" (LIND, 1981, p. 166), revelando-se, de quebra, incapaz de tornar conhecida a proposta poética pessoana nos meios literários europeus, dada a audiência limitada das publicações portuguesas (Idem, ibidem).

O amigo Mário de Sá-Carneiro não deixa de destacar, em carta, o caráter futurista da Ode Triunfal:

\begin{abstract}
Não tenho dúvida em assegurá-lo, meu Amigo, você acaba de escrever a obra-prima do Futurismo (...) pelo menos a partir de agora o Marinetti é um grande homem... porque todos o reconhecem como fundador do futurismo, e essa escola produziu a sua maravilha. Depois de escrita a sua ode, meu querido Fernando Pessoa, eu creio que mais nada de novo se pode escrever para cantar a nossa época (SÁ-CARNEIRO, 1978, p. 152).
\end{abstract}

Considerando a oposição entre as formulações do heterônimo e a materialidade de seu texto, cabe observar em que medida o desdobramento do "eu", embutido na perspectiva artística e conceitual de Campos, guarda relações com o futurismo de Marinetti ou se afasta dele. Para tanto, tomar-se-á como base o poema Ode Triunfal, aquele que inaugura a segunda fase de tal artista imaginário e o faz mergulhar, de fato, na pluralidade vertiginosa de sensações do mundo moderno.

\title{
O louvor febril da modernidade
}

Considerando-se os gêneros de discurso prescritos pela retórica aristotélica, o poema Ode Triunfal pode ser enquadrado no gênero epidítico, pois nele toma corpo uma espécie de encômio arrebatado, dirigido à modernidade, com destaque para o louvor à máquina e à velocidade, o que, de maneira geral, coaduna-se com as propostas de Marinetti. Como se sabe, este último partia do pressuposto de que o poeta deveria inebriar-se com os maquinismos e com a velocidade da vida contemporânea, vislumbrando um outro tipo de literatura. Se, até então, valorizava-se a "imobilidade pensativa, o êxtase e o sono", a arte moderna, em sentido oposto, deveria "exaltar o movimento agressivo, a insônia febril, o passo de corrida, o salto mortal, o bofetão e o soco" (MARINETTI, 1980, p. 33) ${ }^{9}$.

\footnotetext{
${ }^{9}$ No presente artigo, quando se alude a "propostas futuristas" ou a "teses futuristas", consideram-se, sobretudo, os textos "Fundação e manifesto do futurismo", exposição inicial dos princípios estéticos defendidos por Filippo Tommaso Marinetti, cuja publicação deu-se em 20 de fevereiro de 1909, no jornal francês Figaro; e o "Manifesto técnico da literatura futurista", publicado pelo mesmo autor, em 11 de maio de 1912. Ambos foram recolhidos em O futurismo italiano (1980), livro organizado por Aurora Bernardini (ver bibliografia). Como se sabe, a vanguarda futurista foi marcada por dissensões. Em 1914,
} 
Em perspectiva semelhante, Campos constrói para si a imagem de um poeta em estado febril, como se ele fosse o único capaz de se identificar com o hino das máquinas trepidantes e, dessa maneira, cantá-lo. Mais do que isso, ao valer-se da construção de um ethos erótico-emotivo, visando à expressão das fortes sensações despertadas pela civilização industrial, o artista mostra-se em fusão com o universo descrito, como se a ele coubesse amalgamar num gesto poético próprio e onívoro todo esse novo mundo que se descortinava à sua frente:

\author{
Ah, poder exprimir-me todo como um motor se exprime! \\ Ser completo como uma máquina! \\ Poder ir na vida triunfante como um automóvel último modelo! \\ Poder ao menos penetrar-me fisicamente de tudo isto, \\ Rasgar-me todo, abrir-me completamente, tornar-me passento \\ A todos os perfumes de óleos e calores e carvões \\ Desta flora estupenda, negra, artificial e insaciável! (PESSOA, 1977, p. 306)
}

O poeta manifesta o desejo de absorver o universo maquínico descrito, como se tal movimento fosse necessário à captação da "beleza nova" anunciada por Marinetti: a "beleza da velocidade". Para o artista italiano, "um automóvel rugindo" seria o objeto símbolo dessa nova estética. Em sua prosa combativa, o teórico futurista chega a afirmar que os carros motorizados, espécies de "feras bufantes" metálicas, revelar-se-iam mais belos ao condensar o dinamismo contagiante do novo século, do que, por exemplo, a Vitória de Samotrácia, uma das esculturas símbolo da Antiguidade. Analogamente, na apreensão do fenômeno moderno, Campos pretende exprimir-se como um motor e "ir na vida triunfante como um automóvel último modelo!”. Nota-se, portanto, que a magnificência presente no título do poema (uma ode, que além do entusiasmo naturalmente esperado, seria "triunfal") reaparece condensada na experiência proporcionada pelos veículos automobilísticos.

A tematização da atmosfera revolucionária das grandes capitais, com destaque não só para a glorificação das descobertas tecnológicas e científicas, mas também para o caráter fluido e múltiplo das multidões, é outro ponto de aproximação entre os dois autores. $\mathrm{Na}$ última tese enumerada em "Fundação e manifesto do futurismo", Marinetti destaca: "Nós cantaremos as grandes multidões agitadas pelo trabalho, pelo prazer ou pela sublevação;

Giovanni Papini já publicava a obra L'esperienza futurista, na qual procurava tecer distinções entre uma suposta essência do movimento e o marinettismo. Sem entrar no mérito de tais oposições, sobretudo em função dos limites restritos deste texto, o foco se restringirá às concepções de Marinetti, tendo em vista, sobretudo, a ressonância e a influência das diretrizes propostas por seus manifestos de 1909 e 1912. 
cantaremos as marés multicores e polifônicas das revoluções nas capitais modernas" (MARINETTI, 1980, p. 34). Por seu turno, Campos contamina-se por esse frenesi, mergulhando em meio à turba, "nas ruas cheias de encontrões": "Ó multidões cotidianas nem alegres nem tristes das ruas, / Rio anônimo e multicolor e onde eu posso banhar como quereria!” (PESSOA, 1977, p. 309).

Ainda no campo das aproximações entre os textos ora analisados, a força apareceria como um princípio estético básico para Marinetti, sendo que para ele a arte não deveria ser mais que "violência, crueldade e injustiça" (MARINETTI, 1980, p. 36). De maneira semelhante, Campos, ao expressar a ideia de uma devoção praticamente incondicional à ebulição e ao eterno movimentar do mundo moderno, também incluiria em seu canto as facetas mais obscuras da modernidade, a qual seria marcada por corrupções, escândalos financeiros, agressões políticas nas ruas, regicídios, crimes de toda ordem que ganhavam destaque na imprensa, veículo importante dessa época de mudanças. Acima de qualquer consciência de classe, o poeta diz amar os excluídos, parte necessária do cenário selvático dos grandes centros urbanos - "Maravilhosa gente humana que vive como cães, / que está abaixo de todos os sistemas morais". Percebe-se, portanto, que a exaltação do progresso dispensa qualquer ideologização. Além disso, depois de referir-se a desastres, desabamentos, naufrágios, injustiças, violências e até mesmo ao fim do continente europeu, após a invasão de bárbaros amarelos, diz o poeta: "Que importa tudo isto (...), salvo o Momento" (PESSOA, 1977, p. 310). Seu poema ainda seria marcado pela tematização das "brutal sensations, cruelty and lust", patente nas visões sadistas e masoquistas que perpassam o texto. Tais imagens, além de dialogarem com as propostas futuristas aqui tematizadas, revelam ainda certa herança decadentista do poeta, já anunciada no Opiário (D’ONOFRIO e ÁRABE, 1980, p. 64).

Quanto à composição do texto propriamente dito, Álvaro de Campos lança mão de procedimentos artísticos que procuram mimetizar o caráter frenético da modernidade. $\mathrm{O}$ ritmo é livre em função de sua adequação ao volume vertiginoso com que se desencadeiam, no interior do poeta, as imagens oriundas das sensações evocadas pelas máquinas e pela velocidade do mundo moderno. Nesse sentido, predominam versos livres e brancos, com destaque para enunciados longos e descritivos.

Ao mesmo tempo, seu texto é marcado por sucessivas frases exclamativas, por onomatopeias que pretendem reproduzir os ruídos das máquinas trepidantes (r-r-r-r-r-r; Zz-Z-z-Z-Z-Z-Z-Z-Z-z-z!), por interjeições (sobretudo, “eia” e "eh", que, em geral, exprimem 
ânimo, excitação, surpresa), pelo uso de apóstrofes que se reportam a itens do mundo moderno, em recorrentes prosopopeias - "Ó rodas, ó engrenagens”, “ó grandes ruídos modernos”, “ó máquina”, “ó fábricas”, “ó laboratórios”, “ó music-halls”, “ó couraçados”, “ó docas flutuantes”, “ó ferro”, “ó aço”, etc. Com relação a este último aspecto, observa-se que o artista, em estilo declamatório, vale-se da forma da invocação, mas ao invés de dirigir-se às musas para que seu poema obtivesse um resultado sublime, reporta-se a itens do mundo moderno, personificando-os, o que acaba reforçando o efeito de irmandade e fusão de Campos com o universo a que se refere. Paralelamente, dentro dessa mesma chave, também predominam, ao longo da Ode Triunfal, a justaposição de objetos e imagens dos mais heterogêneos, em enumerações caóticas e caleidoscópicas, fazendo com que o eulírico se expanda numa identificação com todas as coisas, deixando-se levar pelo dinamismo e pela onipresença vertiginosa da civilização industrial.

Conforme sublinha Jacinto do Prado Coelho, esse estilo esfuziante, torrencial, interjetivo, anafórico e exclamativo, pautado por certa utopia universalizante, revelaria outro intertexto basilar para a compreensão da Ode Triunfal: a poesia de Walt Whitman. Mais especificamente, a estratégia compositiva de Campos procura, entre outros aspectos, mimetizar a vitalidade explosiva e transbordante, bem como a volúpia imaginativa do poeta norte-americano $^{10}$. E aí as influências se cruzam, pois, não por acaso, quando se consideram as matrizes da representação vertiginosa das sensações modernas, o próprio Marinetti já havia reconhecido o caráter precursor e influente do autor de Levaes of Grass (COELHO, 1977, p. 69).

\section{Dissonâncias: tradição, sintaxe e psicologia}

Apesar de se valer dos referidos procedimentos estilísticos, os quais repercutem em alterações na estruturação sintática e na pontuação tradicionais do texto, Campos parece recusar a proposta de Marinetti, de que a poesia renunciasse a toda e qualquer coordenação das sensações desconexas ${ }^{11}$. De um ponto de vista geral, Pessoa aparenta manifestar

\footnotetext{
${ }^{10} \mathrm{O}$ influxo do intertexto whitmaniano na poesia de Campos torna-se explícito em Saudação a Walt Whitman (1916), poema endereçado ao poeta norte-americano, no qual se escancara a proposta sensacionista: "E, conforme tu sentiste tudo, e cá estamos de mãos dadas, / De mãos dadas, Walt, de mãos dadas, dançando o universo na alma" (PESSOA, 1977, p. 336).

${ }^{11}$ Como destaca Marinetti, no "Manifesto técnico da literatura futurista", seria "preciso destruir a sintaxe colocando os substantivos a olho, conforme eles vão nascendo" (MARINETTI, 1980, p. 81). E mais a frente: "como toda espécie de ordem é fatalmente um produto da inteligência cautelosa e prevenida é
} 
aversão às orgias linguísticas da vanguarda modernista, tendo em vista sua postura de poeta fundamentalmente cerebral, avesso ao banimento de ideias e princípios lógicos da poesia ${ }^{12}$.

Contudo, o maior afastamento entre a Ode Triunfal e as diretrizes futuristas dá-se no tratamento e no papel dispensados à tradição. Marinetti, em sua sanha combativa, recusa, com largas pitadas de ódio, o passado. Repudia os museus e outras instituições fundadas no culto de fatos e acontecimentos pretéritos, que, segundo ele, apenas proporcionariam o envenenamento e o apodrecimento de seus visitantes. Nesse movimento, o poeta coloca num mesmo patamar cemitérios e museus: ambos cultivariam a morte, o estatismo, o retorno infrutífero aos tempos idos - "Admirar um quadro antigo equivale a despejar nossa sensibilidade numa urna funerária, em lugar de projetá-la longe, em violentos jatos de criação e de ação" (MARINETTI, 1980, p. 35). E não fica por aí: em linhas ainda mais claras e contundentes, conclama seus pares: “...nós não queremos saber mais nada do passado, nós, jovens e fortes futuristas!..." (Idem, ibidem).

Campos, por outro lado, evoca e inclui, na exaltação do mundo da máquina, a tradição. Nesse sentido, não proporia uma ruptura com o passado, mas sim a incorporação e a superação dos tempos idos. Grandes nomes da antiguidade, como Virgílio, Platão, Alexandre Magno, Ésquilo, todos eles estariam incluídos na estrutura dos próprios maquinismos com os quais o poeta se depararia no mundo moderno. "Canto, e canto o presente, e também o passado e o futuro / Porque o presente é todo o passado e todo o futuro" (PESSOA, 1977, p. 306). Álvaro de Campos, portanto, tem em vista o caráter sincrético e amplo do presente, que englobaria tanto a história como aquilo que estaria por vir.

Tendo em vista o peso atribuído pelo poeta à grandeza do passado, pode-se falar que Campos preconizaria, de modo paradoxal, certo "futurismo saudosista", pois, ao invés de absolutizar os tempos vindouros, tomaria o porvir como uma espécie de recuperação mítica de glórias pretéritas (PERRONE-MOISÉS, 2008, p. 304). No manifesto Ultimatum, tal perspectiva consolida-se e ganha cores locais na medida em que o cosmopolitismo do poeta cede espaço a certo lusitanismo, no qual se faz presente a noção de utopia messiânica (Idem, ibidem).

necessário orquestrar as imagens dispondo-as de acordo com um MAXIMUM DE DESORDEM" (Idem, p. 84).

${ }^{12}$ Conforme destaca o próprio Campos, em carta ao diretor do jornal lisboeta Diário de Notícias, datada de 4 de junho de 1915, a Ode Triunfal se aproximaria do futurismo tão somente pelo assunto, mas não pela realização - "e em arte a forma de realizar é que caracteriza e distingue as correntes e as escolas" (PESSOA, 1990, p. 154). 
Em carta enviada a Marinetti, provavelmente em 1917, Pessoa explicita sua discordância frente ao exclusivismo e à abordagem histórica proposta pelos mandamentos futuristas:

Eu já havia tomado conhecimento de alguns dos manifestos que você me enviara e que lhe agradeço muito. [...] Em conseqüência, não sou totalmente ignorante em assunto de futurismo; estou mesmo até certo ponto do lado de vocês. Penso, porém, que o futurismo deveria desenvolver-se bastante e abandonar seu extremo exclusivismo. Pareceme que a idéia que vocês formam da história é bem pouco futurista e se afiguram um desenvolvimento histórico por demais regular (PESSOA, 1990, p. 302).

De maneira geral, o poeta português aparenta questionar a perspectiva teleológica defendida pelo futurismo, que recusava todo o passado (visto enquanto um tempo estático, regular e monótono), em prol da suposta ruptura marinettiana, a qual, enfim, teria sido a única capaz de captar a essência do mundo moderno. Portanto, segundo a óptica pessoana, Marinetti, ao negar sistematicamente a tradição e ao defender a emergência de um novo ideal artístico, acabava assumindo posturas demasiadamente excludentes e limitadoras.

Entre as divergências fundamentais entre a perspectiva de Campos e a do teórico futurista tem-se ainda o tratamento conferido à personalidade. Marinetti pregava a necessidade radical de destruir o "eu" na literatura, pois "o homem completamente avariado pela biblioteca e pelo museu" não ofereceria mais nenhum interesse. Segundo ele, as atenções deveriam se voltar para a matéria, para os "objetos em liberdade" (MARINETTI, 1980, p.84). Em termos políticos, tal abolição da psicologia individual proposta pelo teórico italiano coincidia com os propósitos totalitários do fascismo de Mussolini (PERRONE-MOISÉS, 2008, p. 304).

Por seu turno, em oposição a Marinetti, Campos defende a proliferação das virtualidades subjetivas de cada homem. O poeta advogava contra o ideal monolítico de personalidade, prevendo não a demolição, mas sim a emergência de um "eu” múltiplo, que se fragmentaria em meio ao turbilhão de sensações do mundo moderno. Segundo ele, tal psicologia sincrética e multifacetada procuraria abarcar a amplitude vertiginosa da era da máquina, assim como sinaliza o poeta ao fim da Ode Triunfal: "Eia e hurrah por mim-tudo e tudo, máquinas a trabalhar, eia! / Galgar com tudo por cima de tudo! Hup-lá!” (PESSOA, 1977, p. 311). Impõe-se, portanto, a perspectiva de "sentir tudo de todas as maneiras", de 
um "eu" que, cada vez mais, procura ter todas as opiniões e "ser sincero contradizendo-se a cada minuto" (Idem, p. 347).

\section{Conclusão}

Há aproximações entre as teses futuristas propostas por Marinetti e as diretrizes poéticas adotadas por Álvaro de Campos na Ode Triunfal. De maneira geral, tal intertextualidade tem como eixo principal a exaltação da máquina. Para ambos os autores, os maquinismos se colocariam para além do plano imediato e objetivo: metaforicamente seriam tomados enquanto imagens sínteses por meio das quais se extravasaria toda pulsão erótico-subjetiva, decorrente das múltiplas figuras evocadas pelo imaginário moderno. Se há acordo nesses termos, por outro lado, há dissensão entre o heterônimo pessoano e o combativo futurista, principalmente na ruptura tanto conceitual quanto linguística proposta por este último. Campos, ao contrário de Marinetti, inclui a tradição em seu louvor ao mundo moderno, ao mesmo tempo em que recusa a destruição sintática extrema, pregada pelo teórico italiano.

Além disso, o louvor ao mundo moderno entoado por Campos faz-se segundo uma perspectiva a um só tempo pessoal e fragmentária, em que a glorificação da era das máquinas passaria não pelas coisas, mas sim pelas "sensações das coisas" (PESSOA, 1966, p. 137). Por conseguinte, a objetivação da arte, presente no ideal marinettiano de substituição da psicologia do homem pela "obsessão lírica da matéria” (MARINETTI, 1980, p. 84) não poderia prescindir do sujeito. Na verdade, de acordo com as concepções do poeta, haveria a fusão entre os objetos e o homem, em que o "eu" prismático se desdobraria para englobar a complexidade sensorial da modernidade.

Não por acaso, tal processo de intelecção das sensações, segundo a óptica de uma personalidade cindida, faz com que, gradativamente, os excessos dionisíacos cedam lugar à resignação e ao desapontamento, predominantes na fase derradeira de Campos. Conforme destaca Lind, o desdobramento do "eu", pautado pela fragmentação e pela polifonia, não fora capaz de atingir o Absoluto (LIND, 1981, p. 197). Restou ao poeta aprofundar seu mergulho introspectivo, com privilégio não mais para a irmandade eufórica com o mundo moderno, mas sim para o fosso que o separava da conjunção consigo mesmo. 


\section{Bibliografia}

COELHO, Jacinto do Prado Coelho. Diversidade e unidade em Fernando Pessoa. São Paulo: Verbo; Edusp, 1977.

D’ONOFRIO, Salvatore e ÁRABE, Maria Amélia A. “O sensacionalismo na visão poética de Álvaro de Campos”. Revista de Letras, São Paulo, v. 20, 1980, pp. 59-73.

LIND, Georg Rudolf. Estudos sobre Fernando Pessoa. Trad. Margarida Losa. Lisboa: Imprensa Nacional; Casa da Moeda, 1981.

MARINETTI, F. T. "Fundação e manifesto do futurismo" e "Manifesto técnico da literatura futurista". In: BERNARDINI, Aurora Fornoni (org). O futurismo italiano. São Paulo: Perspectiva, 1980, pp. 31-36 e 81-87.

LOPES, Óscar. Ler e depois: crítica e interpretação literária/1. Porto: Editorial Inova, 1969, pp. 236-284.

PAPINI, Giovanni. L’esperienza futurista. Florença: Vallecchi, 1927.

PESSOA, Fernando. Obras em prosa. Rio de Janeiro: Nova Aguilar, 1990. . Textos de intervenção crítica. Lisboa: Ática, 1980.

. Obra poética. Rio de Janeiro: Nova Aguilar, 1977. . Páginas intimas de auto-interpretação. Lisboa: Ática, 1966 . Páginas de doutrina estética. Lisboa: Editorial Inquérito, 1946.

PERRONE-MOISÉS, Leyla. "Futurismo saudosista". In: MARTINS, Fernando Cabral (coord.). Dicionário de Fernando Pessoa e do modernismo português. Lisboa: Editorial Caminho, 2008. SÁ-CARNEIRO, Mário de. Cartas a Fernando Pessoa. 2 vols. Lisboa: Edições Ática, 1978, vol. 1. 